\title{
Cross-Linguistic Influence on a Bilingual Child's Phonological Development
}

\author{
Ni Luh Putu Sri Adnyani \\ Department of Foreign Languages, Universitas Pendidikan Ganesha, Singaraja, Bali, Indonesia \\ Corresponding author. Email: niluhputusriadnyani@gmail.com
}

\begin{abstract}
Cross-linguistic influences (CLIs) are the effects of one language on another where a grammatical property from one language is incorporated into the other. This paper investigates CLI occurring in an Indonesian-German bilingual child's speech, particularly from the aspect of phonology. The data has been collected from the bilingual child between the ages of 20 months and 36 months. In the child's language development, Indonesian is the dominant language. In collecting the data, diary records and weekly video recording were conducted. The study shows that there are five sounds in Indonesian used to replace particular German sounds: 1) the affricate [č] is used to substitute $/ \mathrm{J} /, / \mathrm{z} /$ and $/ \mathrm{s} / ; 2)$ the semivowel $[\mathrm{w}]$ is used to replace $/ \mathrm{v} / ; 3$ ) the semivowel $[\mathrm{y}]$ replaces the sound $[\mathrm{Y}] ; 4)$ the fricative $[\mathrm{s}]$ substitutes $/ \mathrm{J} /$ and $\mathrm{zz} /$; and 5) the vowel [a] is used to substitute / $\mathrm{r} /$. The study confirms that CLI occurs in the domain of phonology in simultaneous bilingual development.
\end{abstract}

Keywords: CLI, bilingual child, phonology

\section{INTRODUCTION}

There have been a growing number of theories concerning the two linguistic systems that develop when a child becomes bilingual. One of the earliest theories, proposed by Volterra and Taeschner (1978), suggests that a bilingual child initially develops a single linguistic system underlying the two languages. The theory is supported by Schnitzer and Krasinski (1994) at the phonological level, Clark (1987) at the lexical level, and Redlinger \& Park (1980) at the syntactic level. However, the theory was opposed by a number of researchers who have given evidence that the fused system (i.e., the unitary language system hypothesis) was not correct. Bosch and Sebastán-Gallés (2001, 2003) revealed that Spanish and Catalan bilingual children can differentiate the two closely related languages in phonology. Other researchers showed signs of language differentiation in children's lexicons (Deuchar \& Quay, 2000) and at the syntactic level (De Houwer, 1990; Meisel, 1989; Mishina-Mori, 2002).

Although the assumption that bilingual children develop separate linguistic systems is generally accepted, the possibility that the children's linguistic systems may influence each other has become the focus of growing number of recent studies. In bilingual first-language acquisition, cross-linguistic influence (CLI) is a term used to describe the 'mixed' speech that may exist when two languages a speaker knows influence each other. CLI may be determined by external factors such as language dominance, language-internal factors or a combination of both. CLI may occur where a child's stronger language influences the weaker language. Yip and Matthews (2000) showed that in Cantonese-English bilingual speech, syntactic transfer can occur that is determined by language dominance. In another study, Yip and Matthews (2007) revealed that in bilingual children, Cantonese was the stronger language, which extensively interfered in the spoken English, their weaker language. Soriente (2014) showed CLI experienced by a child exposed to Jakarta Indonesian and Italian. It was reported that the influence occurred due to dominance of Indonesian. Other researchers reveal that CLI is determined by languageinternal factors, where the two languages have similar underlying structures (Hulk \& Müller, 2000). Döpke (1998) found out that German-English bilinguals transfer English syntax to German, resulting from the superficial syntactic similarity in the two languages. A study conducted by Serratrice, Sorace, and Paoli (2004) also confirms that language-internal factors influence CLI in English-Italian bilinguals.

While the aforementioned pieces of research can be divided into those supporting dominance or languageinternal structure in determining CLI, more current 
research reveals that both factors are combined in affecting CLI. A combination of language dominance and language-internal factors influences bilingual children's cross-linguistic speech, as is supported by Kupisch (2007) in German-Italian bilingual children, Ge, Matthews, Cheung, and Yip (2017) in Cantonese-English bilingual children, and Adnyani, Beratha, Pastika, and Suparwa (2018) in Indonesian-German bilingual child. Most of the studies that confirm that CLI occurs in bilingual language development mainly focus on lexical or syntactic development. Limited research has been conducted to observe CLI on phonological levels. Adnyani and Pastika (2016) conducted a study into the aspect of phonological development in an IndonesianGerman bilingual child. The study found out that the German front rounded vowel $[\mathrm{Y}]$ was replaced by the Indonesian palatal approximant [j]. The study was carried out when the child was between 12 and 20 months old. The present study is a continuation of the study conducted by Adnyani and Pastika (2016); the data has been collected from a child between the ages of 20 months and 36 months. Additional research in children's Indonesian-German phonological development needs to be conducted to look at a possible CLI occurring in other sound segments as the child grow older. This study also observes the factors that determine CLI, particularly in the development of the child's phonological systems.

\section{METHOD}

This research is a case study of a bilingual child exposed to Indonesian and German since birth. The child, Alyssa (ALY) lives in an Indonesian-speaking environment. The mother was born in Indonesia, and the father was born in Germany. The mother exclusively addresses her in Indonesian, and the father in German. In the family, the parents mostly talk to each other in Indonesian since the father speaks the language fluently while the mother is less proficient in German. The child also interacts with her sister, who speaks four languages fluently: Indonesian, German, English and Balinese. The German language is also used by her grandmother and her uncle, via Skype. They interact via Skype regularly. In comparison, Indonesian is dominant, with more people interacting with the child in Indonesian than in any other language. Other people speaking Indonesian to the child are a babysitter who looks after the child while the mother is working, and other extended family members from the mother's side, who frequently visit the family.

Data was collected from the child between the ages of 20 months and 36 months. Data was gathered from conversational text based on spontaneous communication among family members. The data was collected in the form of diary records, supplemented by video recordings. The records are in the form of orthographic notes accompanied by their phonetic transcriptions, as well as contextual information. The child's speech, which has become the focus of analysis in this study, was segmented based on utterances. Segmenting speech based on utterances was adapted from the work of Lanza (1992). In analysing the data, ELAN and Toolbox were used as instruments. Two students from the faculty of languages and arts at the Universitas Pendidikan Ganesha helped to transcribe the data. The child's speech is identified and then narrated, interpreted and discussed.

\section{FINDINGS AND DISCUSSION}

Indonesian and German are two typologically different languages. Indonesian has six vowel phonemes, namely the front high vowel /i/, the front medium vowel /e/, the central medium vowel /a/, the central low vowel $/ \mathrm{a} /$, the medium high vowel $/ \mathrm{u} /$ and the back medium vowel /o/, as shown in Figure 1. Indonesian has 22 consonant phonemes that are grouped based on three factors, which are place of articulation, manner of articulation and whether the vocal cord is open or closed (Alwi, Lapoliwa, \& Darmowidjojo, 2003). Consonant phonemes in Indonesian can be represented in a table, as shown in Table 1.

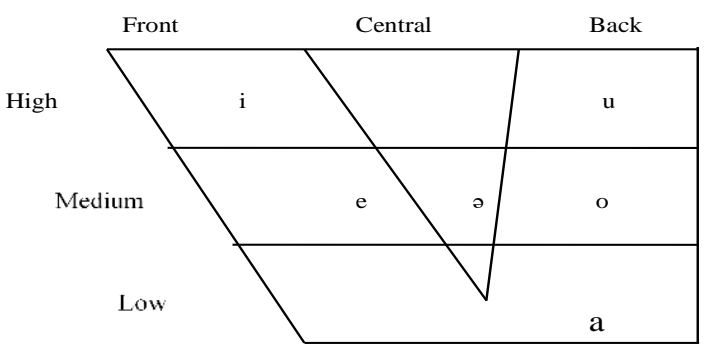

Figure 1 Vowels in Indonesian.

Table 1. Consonant phonemes in Indonesian

\begin{tabular}{|c|c|c|c|c|c|c|c|}
\hline $\begin{array}{l}\text { Manner } \\
\text { of Articulation }\end{array}$ & $\begin{array}{l}\text { Point } \\
\text { of Articulation }\end{array}$ & Bilabial & Labiodental & Alveolar & Palatal & Velar & Glottal \\
\hline \multirow[t]{2}{*}{ Stop } & Voiceless & $\mathrm{p}$ & & $\mathrm{t}$ & & $\mathrm{k}$ & \\
\hline & Voiced & b & & $\mathrm{d}$ & & $\mathrm{g}$ & \\
\hline \multirow[t]{2}{*}{ Fricative } & Voiceless & & $\mathrm{f}$ & $\mathrm{s}$ & $\check{\mathrm{s}}$ & $\mathrm{x}$ & $\mathrm{h}$ \\
\hline & Voiced & & & $\mathrm{z}$ & & & \\
\hline \multirow[t]{2}{*}{ Affricate } & Voiceless & & & & $\check{c}$ & & \\
\hline & Voiced & & & & $\hat{\jmath}$ & & \\
\hline Nasal & Voiced & & $\mathrm{m}$ & $\mathrm{n}$ & $\tilde{\mathrm{n}}$ & $\mathrm{y}$ & \\
\hline Trill & Voiced & & & $\mathrm{r}$ & & & \\
\hline Lateral & Voiced & & & 1 & & & \\
\hline Semivowel & Voiced & & $\mathrm{W}$ & & $\mathrm{y}$ & & \\
\hline
\end{tabular}




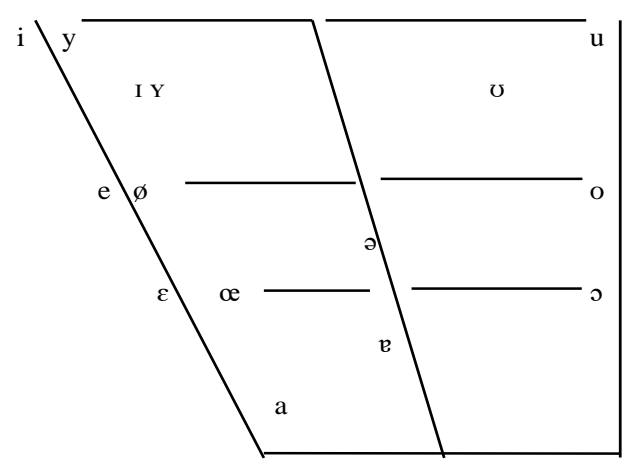

Figure 2 Vowels in German.

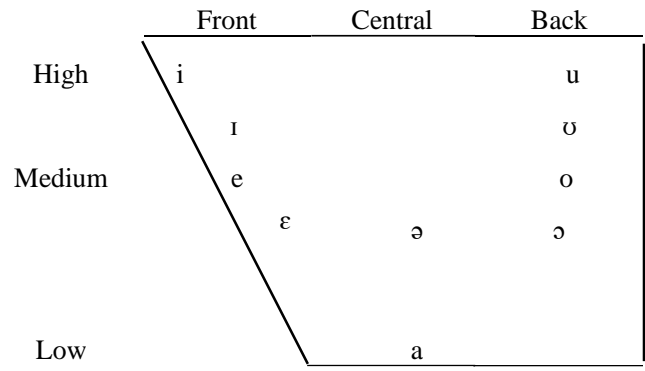

Figure 3 Indonesian vowels at the multi-word utterance stage.
Compared to Indonesian, German has more vowel sounds. Vowel sounds in German have been explained by Ladefoged (2001) and The University of Iowa (2014), as shown in Figure 2. In terms of consonant sounds, standard German has 22 (Battenburg \& Swanson, 2000), as represented in Table 2. At the age of 1;9 (21 months), the child started to produce multi-word utterances in Indonesian. On the other hand, the child started to produce these multi-word utterances in German around the age of 2;6 (30 months). At the multi-word utterance period in Indonesian, 20 consonants were developed by ALY.

In terms of the manner of articulation, the acquired consonants consisted of seven stop consonants, three fricative consonants, two affricate consonants, four nasals, one lateral, one trill and two semivowels. In terms of place of articulation, the consonants produced by ALY consisted of four bilabial consonants, one labiodental, six alveolars, four alveopalatals, three velars and two glottal consonants. The 20 consonants that ALY had acquired can be seen in Table 3. At the multi-word utterance stage, all vowel sounds found in standard Indonesian had been acquired by ALY. The list of the vowel sounds that had been acquired by her can be seen in Figure 3 .

Table 2. Consonant phonemes in German

\begin{tabular}{|c|c|c|c|c|c|c|c|c|c|}
\hline $\begin{array}{c}\text { Manner } \\
\text { of Articulation }\end{array}$ & $\begin{array}{c}\text { Point } \\
\text { of Articulation }\end{array}$ & Bilabial & Labiodental & Alveolar & $\begin{array}{c}\text { Post } \\
\text { alveolar }\end{array}$ & Palatal & Velar & Uvular & Glottal \\
\hline \multirow[t]{2}{*}{ Stop } & Voiceless & $\mathrm{p}$ & & $\mathrm{t}$ & & & $\mathrm{k}$ & & $?$ \\
\hline & Voiced & $\mathrm{b}$ & & d & & & $\mathrm{g}$ & & \\
\hline \multirow[t]{2}{*}{ Fricative } & Voiceless & & $\mathrm{f}$ & $\mathrm{s}$ & $\int$ & ç & $\mathrm{x}$ & & $\mathrm{h}$ \\
\hline & Voiced & & $\mathrm{v}$ & $\mathrm{z}$ & 3 & $\mathrm{j}$ & & в & \\
\hline Nasal & Voiced & $\mathrm{m}$ & & $\mathrm{n}$ & & & $\mathrm{y}$ & & \\
\hline Lateral & Voiced & & & 1 & & & & & \\
\hline
\end{tabular}

Table 3. Phonetic sounds in Indonesian at the multi-word utterance stage

\begin{tabular}{|c|c|c|c|c|c|c|c|}
\hline $\begin{array}{c}\text { Point/Manner } \\
\text { of Articulation }\end{array}$ & Bilabial & Dental & Labiodental & Alveolar & Alveopalatal & Velar & Glottal \\
\hline \multirow[t]{2}{*}{ Stop } & $\mathrm{p}$ & & & $\mathrm{t}$ & & $\mathrm{k}$ & $?$ \\
\hline & $\mathrm{b}$ & & & d & & $\mathrm{g}$ & \\
\hline Fricative & & $\Theta$ & $\mathrm{f}$ & $\mathrm{s}$ & & & $\mathrm{h}$ \\
\hline \multirow[t]{2}{*}{ Affricate } & & & & & $\check{c}$ & & \\
\hline & & & & & $\hat{\jmath}$ & & \\
\hline Nasal & $\mathrm{m}$ & & & $\mathrm{n}$ & $\tilde{\mathrm{n}}$ & $y$ & \\
\hline Lateral & & & & 1 & & & \\
\hline Trill & & & & (r) & & & \\
\hline Semivowel & W & & & & $\mathrm{y}$ & & \\
\hline
\end{tabular}


Table 4. Phonetic sounds of German consonants at the multi-word utterance stage

\begin{tabular}{|c|c|c|c|c|c|c|c|c|}
\hline Point/ manner of Articulation & Bilabial & Labiodental & Alveolar & Post alveolar & Palatal & Velar & Uvular & Glottal \\
\hline \multirow[t]{2}{*}{ Stop } & $\mathrm{p}$ & & $\mathrm{t}$ & & & $\mathrm{k}$ & & $?$ \\
\hline & $\mathrm{b}$ & & $\mathrm{d}$ & & & $\mathrm{g}$ & & \\
\hline \multirow[t]{2}{*}{ Fricative } & & $\mathrm{f}$ & $\mathrm{s}$ & $\int$ & ç & $\mathrm{x}$ & & $\mathrm{h}$ \\
\hline & & $\mathrm{v}$ & $\mathrm{z}$ & & $\mathrm{j}$ & & в & \\
\hline Nasal & $\mathrm{m}$ & & $\mathrm{n}$ & & & $\mathrm{y}$ & & \\
\hline Lateral & & & 1 & & & & & \\
\hline
\end{tabular}

On the other hand, in German, ALY started the multiword utterance stage at around the age of $2 ; 6$. This shows that there was a difference in time of approximately seven months compared to her Indonesian development. At this stage, there were 21 consonants in German that ALY had acquired. The 21 consonants that she had acquired, in terms of manner of articulation, consisted of seven stop consonants, ten fricative consonants, three nasals and one lateral, while in terms of place of articulation, the consonants that she had acquired consisted of three bilabials, two labiodentals, six alveolars, one postalveolar, two palatals, four velars, one uvular and two glottal consonants. The 21 consonants that she had acquired in German at the multi-word stage can be seen in Table 4. At the multi-word utterance stage, the number of vowels sounds in German that ALY had acquired was thirteen. The vowel sounds were [a, i, I, e, $\varepsilon, \mathrm{y}, \mathrm{y}$, ə, u, $\mathrm{u}$, $\mathrm{o}, \mathrm{\rho}, \mathrm{e}]$. There were two vowels in standard German that she did not acquire until the age of 3;0. All the vocal sounds that ALY had acquired can be seen in Figure 4.

In the child's phonological development, it was observed that the child experienced sounds system interference from the dominant language, Indonesian, to the weaker language, German. The child transferred Indonesian sounds to her German language production. Transfer is a form of CLI (Genesee, 2001; Yip, 2013). The CLI from Indonesian to German can be seen in the following details.

\subsection{Transfer of the affricate consonant [č ]}

In her German language development, ALY often transferred the affricate consonant [ $[\check{c}]$ into the production of words in German. The transfer of the affricate sound, which is actually a sound found in the Indonesian phonetic system, can be seen in Table 5. It can be said that affricate sound [ $\check{\mathrm{c}}$ ] was used to substitute the fricative sounds of $/ \mathrm{J} / \mathrm{,} / \mathrm{z} /$ and $/ \mathrm{s} /$. RD in the table is the underlying representation and RF is the phonetic realization. As has been described in the previous section, ALY tended to replace fricative sounds that she had not acquired with stop sounds or affricate sounds.

It turns out that this was also done by ALY on fricative sounds in German, as she replaced them with the affricate sound found in Indonesian. In German, there is no affricate sound [ᄃ̌c]. Thus, ALY did not only replace the fricative sounds that are found in Indonesian with an affricate sound, but she also did the same thing in her German.

\subsection{Transfer of the semivowel consonant [w]}

ALY was also identified to have transferred the semivowel sound $[w]$, which is found in the Indonesian phonetic system, into her production of words in German. German, of course, does not have the semivowel sound /w/. The transfer of the [w] sound into the production of ALY's German can be shown in Table 6 .

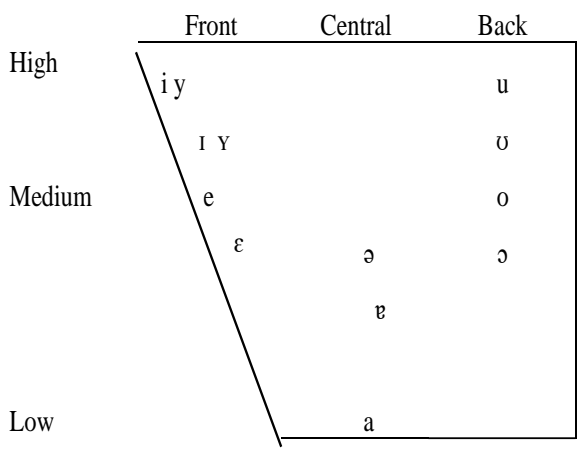

Figure 4 Phonetic sounds in German at the multi-word utterance stage

Table 5. Transfer of the affricate consonant [č

\begin{tabular}{|c|c|c|c|c|}
\hline Age & Word & $\mathrm{RD}$ & $\mathrm{RF}$ & Meaning \\
\hline $1 ; 9.26$ & Michelle & $/ \mathrm{mi} \int \varepsilon \mathrm{l} /$ & [mičsn] & Michelle \\
\hline $1 ; 9$ & Salz & /zalts/ & [čan] & salt \\
\hline $1 ; 9$ & Zimmer & /tsime/ & [čimə] & room \\
\hline $1 ; 10$ & Wasser & /vase/ & [wače] & water \\
\hline
\end{tabular}

Table 6. Transfer of the semivowel sound [w]

\begin{tabular}{lllll}
\hline \multicolumn{1}{c}{ Age } & Word & RD & RF & Meaning \\
\hline $1 ; 9.16$ & Wurst & /vorst/ & [wost] & sausage \\
$1 ; 10$ & Wasser & /vase/ & [wače] & water \\
$1 ; 11.16$ & Wenig & /ve:nıç/ & [we:ni] & a little \\
$1 ; 11.9$ & Wider & /vi:de/ & [wida] & again \\
$2 ; 2.12$ & Wir & /vi:e/ & [wi] & we \\
\hline
\end{tabular}


In Table 6, it can be seen that the semivowel sound [w] was used by ALY to replace the labiodental fricative sound /v/. The labiodental sound /v/ does not exist in Indonesian, but the sound does exist in German. As has been discussed before, in its initial development, it tends to be very difficult for a child to pronounce fricative sounds, including the labiodental fricative /v/. When producing the fricative sound $/ \mathrm{v} /$, a child has to move his or her lower lip to touch the upper tooth edge; simultaneously, he or she has to be able to rub the air that is coming out of his or her lungs through a narrow passage between the lower lip and the tooth edge. In her initial development, ALY faced a problem producing that sound.

Hence, the child tried to find a way to produce that sound. One of the ways used was replacing that sound with a sound that is easier to pronounce. In this case, the fricative sound /v/ was replaced by ALY with the semivowel sound [w]. In pronouncing the semivowel sound [w], ALY only needed to move both of her lips to form a rounded shape and release the wind that exits from the lungs in that way. Leopold (1978) found that in the language development of a child who acquired the two languages of English and German simultaneously, the fricative sound $/ \mathrm{v} /$ started to be acquired by the child at the age of $2 ; 4$.

\subsection{Transfer of semivowel consonant sound [y]}

In addition to the transfer of the affricate sound [ $\check{\text { c }}$ ] and the semivowel sound [w], ALY also transferred the semivowel sound [y]. The transfer of the semivowel sound [y] can be seen in Table 7. In Table 7, it can be seen that although the replacement of the front rounded vowel $[\mathrm{Y}]$ by the semivowel sound [y] was only found in the production of the word 'Feuer' [poye], this substitutional process occurred continuously and took place over a relatively long time in the child's language development process. Other words that contain high front rounded vowel sounds had not yet been produced by ALY. Fikkert (2007) explained that when children have difficulties producing particular sounds that might be caused by their articulatory limitation or the acquisition process, the children usually use particular strategies to solve the problem of producing the sounds that they consider difficult.

Thus, for ALY, it was easier to pronounce the semivowel sound [y]. Here, she only needed to move her central tongue closer to her palate, while for producing the high front rounded vowel [Y], the child not only has to move her tongue in this way, but at the same time has to form or position both lips to a form a rounded shape. In addition, the high front rounded vowel [Y] does not exist in the Indonesian phonetic system. In other words, this sound was not often heard by the child, since the source was too limited - in general, she heard it only from her father and her older sister.

\subsection{Transfer of the position of the fricative consonant sound [s]}

In the German phonemic system, the fricative /s/ does not occur in the initial position. The sound $/ \mathrm{s} /$ is distributed in the middle and final position. However, in her German production, the child often places /s/ at the beginning of a word as can be seen in Table 8. It can be said that ALY transferred the [s] word position, because the $[\mathrm{s}]$ sound is very frequently pronounced in the initial word position in Indonesian, so she made it also occur in the initial words in German.

Table 7. Transfer of the semivowel sound [y]

\begin{tabular}{lllll}
\hline Age & Word & RD & RF & Meaning \\
\hline $1 ; 10.9$ & Feuer & /foye/ & [poya] & fire \\
\hline
\end{tabular}

Table 8. Transfer of the position of the fricative consonant sound [s]

\begin{tabular}{lllll}
\hline \multicolumn{1}{c}{ Age } & Word & RD & RF & Meaning \\
\hline $2 ; 3.2$ & Schiff & / fif / & [sip] & ship \\
$2 ; 3.15$ & Sonne & /zonə/ & [sonə] & sun \\
$2 ; 5.1$ & Salat & /zala:t/ & [salat] & salad \\
$2 ; 5.1$ & Sauce & /zo:sə/ & [sosə] & sauce \\
\hline
\end{tabular}

Table 9. Transfer of the position of the fricative consonant sound $[\mathrm{s}]$

\begin{tabular}{lllll}
\hline \multicolumn{1}{c}{ Age } & Word & RD & RF & Meaning \\
\hline $1 ; 7.7$ & Butter & /bote/ & [buta] & butter \\
$1 ; 9.16$ & Messer & $/$ mese/ & [meta] & knife \\
$1 ; 9.16$ & Runter & $/$ ronte/ & [unta] & descend \\
$1 ; 9.16$ & Kinder & $/$ kinde / & [kinda] & kid \\
$1 ; 11.9$ & Wider & $/$ vi:de/ & [wida] & again \\
\hline
\end{tabular}

\subsection{Transfer of the vowel sound [a] position}

In the German phonetic system, the vowel sound [a] does not occur in the final word position except in the word 'da' ('there'), which is the informal form of the word 'dort'. On the other hand, Indonesian is very rich with words with the low vowel sound /a/ in the final word position. However, in producing words in German, ALY often substituted the fortis central-medium $/ \mathfrak{v} /$ with the low vowel [a], as is shown in Table 9. From Table 9, there are two things that can be said about the substitution of the sound $/ \mathrm{e} /$ with the low vowel [a]. First, the [a] sound is easier to be acquired by children. In fact, the [a] sound is the first vowel sound acquired by children acquiring languages around the world. Second, in the case of ALY's language acquisition, this could also become one of the transfer forms since there is dominance of the [a] sound position in the final word in Indonesian which was then transferred in the production of German. 
The next answer that needs to be sought is the reason for the occurrence of transfer in simultaneous bilingual child language development, as had occurred in ALY. One thing that can explain the occurrence of transfer is the dominance of one of the languages that children have acquired. Yip \& Matthews (2007) explained that when the inputs from the two languages that children have acquired are not equal, one of the two languages can develop more quickly or more fully at a certain age. This faster-developing language is called the dominant language. On the other hand, Döpke (1996) described how the weaker language that is acquired by children is the language that is not used by the community in which the children live. In addition, the weaker language develops more slowly and experiences the transfer of linguistic elements from the more dominant one.

In the case of ALY's language development, Indonesian acquisition dominated her language development. In other words, Indonesian became a stronger language and German a weaker one. Hence, the transfer process occurred from the more dominant language to the less dominant one. This is also proven with the nonexistence of the transfer of elements of sounds from German to her production of Indonesian. The effect of the dominant language on the weaker one in simultaneous bilingual child language development was also found by Soriente (2006). Soriente (2006) found that a child she studied had a tendency to use more Indonesian elements than Italian ones in their production of language, because Indonesian was more dominant than Italian, and the latter took the child more time to acquire.

\section{CONCLUSION}

On the basis of a general analysis of these CLIs in terms of phonological development, it can be said that sound transfer occurs from the Indonesian language to the German language. The child never transfers German sounds to the Indonesian sound system. The occurrence of sound transfer in the German production demonstrates that the child's CLI is related to her dominant language. Since exposure to German is more limited than exposure to Indonesian, German's development lags behind. Thus, it takes the child longer to produce all the sounds that exist in the German phonological system.

\section{REFERENCES}

Adnyani, N., \& Pastika, I. (2016). Phonological development in the early speech of an IndonesianGerman bilingual child. Research in Language, 14(3), 329-350.

Adnyani, N., Beratha, N., Pastika, I., \& Suparwa, I. (2018). The development of verbal morphology and word order in an Indonesian-German bilingual child: A case study. Topics in Linguistics, 19(1), 3353.
Battenburg, J. D., \& Swanson , J. (2000). German Consonants. Retrieved from http://ipap.calpoly.edu/gpa/consonants.html

Bosch, L., \& Sebastián-Gallés, N. (2001). Evidence of early language discrimination abilities in infants from bilingual environments. Infancy, 2(1), 29-49.

Bosch, L., \& Sebastián-Gallés, N. (2003). Simultaneous bilingualism and the perception of a languagespecific vowel contrast in the first year of life. Language and speech, 46(2-3), 217-243.

Clark, E. (1987). The Principle of contrast: A constraint on language acquisition. In B. MacWhinney, Mechanism of language acquisition (pp. 1-33). Hillsdale, NJ: Lawrence Erlbaum Associates.

De Houwer, A. (1990). The acquisition of two languages from birth: A case study. Cambridge: Cambridge University Press.

Deuchar, M., \& Quay, S. (2000). Bilingual acquisition. Theoretical implications of a case study. Oxford: Oxford University Press.

Döpke, S. (1996). The weaker language in simultaneous bilingualism: Why it is not like L2. Retrieved from http://www.bilingualoptions.com.au/consTXTL2.p df.

Döpke, S. (1998). Review of Elizabeth Lanza's 'Language Mixing in Infant Bilingualism'. The International Journal of Bilingualism, 2(3), 106109.

Fikkert, P. (2007). Acquiring Phonology. In P. D. Lacy, Handbook of Phonological Theory (pp. 537-554). Cambridge: Cambridge University Press.

Ge, H., Matthews, S., Cheung, L. Y., \& Yip, V. (2017). Bidirectional cross-linguistic influence in Cantonese-English influence bilingual children: The case of right-dislocation. First language, 37(3), 231251.

Genesee, F. (2001). Bilingual first language acquisition: Exploring the limits of the language faculty. Annual review of applied linguistics, 21, 153-168.

Hulk, A., \& Müller, N. (2000). Bilingual first language acquisition at the interface between syntax and pragmatics. Bilingualism: Language and Cognition, $3,227-244$.

Kupisch, T. (2007). Determiners in bilingual GermanItalian children: What they tell us about the relation between language influence and language dominance. Bilingualism: Language and Cognition, 10(1), 57-78. 
Ladefoged, P. (2001). Vowels and consonants: an introduction to the sounds of languages. Massachusetts: Blackwell Publishers.

Lanza, E. (1992). Can bilingual two-years-olds code switch? Journal of Child Language, 19(3), 633-658.

Leopold, W. F. (1978). A Child's Learning of Two Languages. In E. M. Hatch, Second Language Acquisition: A Book of Readings (pp. 23-32). Massachusetts: Newbury House Publishers.

Meisel, J. M. (1989). Early differntiation of languages in bilingual children. In K. Hyltenstam, \& L. K. Obler, Bilingualism Across the Lifespan: Aspects of Acquisition, Maturity, and Loss (pp. 13-40). Cambridge: Cambridge University Press.

Mishina-mori, S. (2002). Language differentiation of the two languages in early bilingual development: A case study of Japanese/English bilingual children. International Review of Applied Linguistics in Language Teaching, 40(3), 211-233.

Redlinger, W. E., \& Park, T. Z. (1980). Language mixing in young bilinguals. Journal of child language, 7(2), 337-352.

Schnitzer, M. L., \& Krasinski, E. (1994). The development of segmental phonological production in a bilingual child. Journal of Child Language, 21(3), 585-622.

Serratrice, L., Sorace, A., \& Paoli, S. (2004). Crosslinguistic influence at the syntax-pragmatics interface: Subjects and objects in English-Italian bilingual and monolingual acquisition. Bilingualism: Language and Cognition, 7(3), 183205.
Soriente, A. (2006). Dominance and language choice in an Indonesian-Italian bilingual child. Naskah Lengkap the Linguistik International, Amsterdam.

Soriente, A. (2014). Language development of bilingual children: A case study in the acquisition of tense and aspect in an Italian-Indonesian child. Wacana, $15(1), 132-165$.

Alwi, H., Lapoliwa, H., Darmowidjojo, S. (2003). Tata Bahasa Baku Bahasa Indonesia. Jakarta: Balai Pustaka.

The University of Iowa. (2014). Phonetik: die laute des deutschen. Retrieved from http://www.uiowa.edu/acadtech/phonetics/german/german.html

Volterra, V., \& Taeschner, T. (1978). The acquisition and development of language bilingual children. Journal of Child Language, 5, 311-326.

Yip, V. (2013). Simultaneous Language Acquisition. In F. Grosjean, The Psycholinguistics of Bilingualism (pp. 119-144). West Sussex: Wiley-Blackwell.

Yip, V., \& Matthews, S. (2000). Syntactic transfer in a Cantonese-English bilingual child. Bilingualism: Language and cognition, 3(3), 193-208.

Yip, V., \& Matthews, S. (2007). The Bilingual Child: Early Development and Language Contact. Cambridge: Cambridge University Press. 